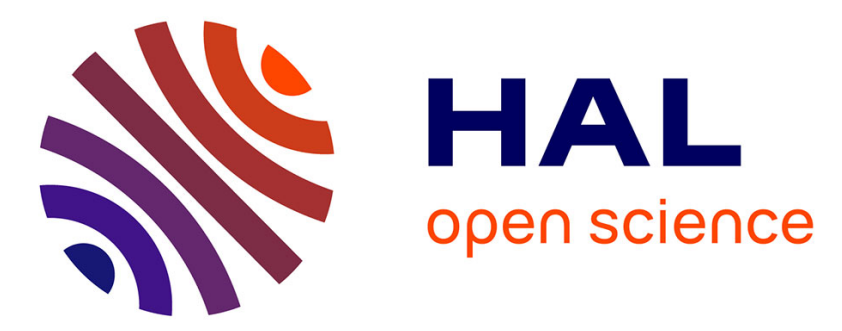

\title{
Counting 'micro-workers': societal and methodological challenges around new forms of labour
}

\author{
Paola Tubaro, Clément Le Ludec, Antonio A. Casilli
}

\section{To cite this version:}

Paola Tubaro, Clément Le Ludec, Antonio A. Casilli. Counting 'micro-workers': societal and methodological challenges around new forms of labour. Work Organisation, Labour \& Globalisation, 2020, 14 (1), pp.67-82. 10.13169/workorgalaboglob.14.1.0067 . hal-02898905

\section{HAL Id: hal-02898905 \\ https://hal.science/hal-02898905}

Submitted on 14 Jul 2020

HAL is a multi-disciplinary open access archive for the deposit and dissemination of scientific research documents, whether they are published or not. The documents may come from teaching and research institutions in France or abroad, or from public or private research centers.
L'archive ouverte pluridisciplinaire HAL, est destinée au dépôt et à la diffusion de documents scientifiques de niveau recherche, publiés ou non, émanant des établissements d'enseignement et de recherche français ou étrangers, des laboratoires publics ou privés.

\section{()ㅜ) $\Theta$}

Distributed under a Creative Commons Attribution - NoDerivatives| 4.0 International 


\section{Counting 'micro-workers': Societal and methodological challenges around new forms of labour}

Paola Tubaro, Clément Le Ludec and Antonio A. Casilli

Paola Tubaro is Associate Research Professor at the Laboratory of Research in Informatics (LRI), CNRS / Université Paris-Saclay / Inria, France.

Clément Le Ludec is PhD student at the Interdisciplinary Institute for Innovation (i3), Telecom Paris, Institut Polytechnique de Paris, France.

Antonio A. Casilli is Professor at the Interdisciplinary Institute for Innovation (i3), Telecom Paris, Institut Polytechnique de Paris, France.

\section{Abstract}

'Micro-work' consists of fragmented data tasks that myriad providers execute on online platforms. While crucial to the development of data-based technologies, this little visible and geographically spread activity is particularly difficult to measure. To fill this gap, we combined qualitative and quantitative methods (online surveys, in-depth interviews, capture-recapture techniques, and web traffic analytics) to count micro-workers in a single country, France. On the basis of this analysis, we estimate that approximately 260,000 people are registered with micro-work platforms. Of these some 50,000 are 'regular' workers who do micro-tasks at least monthly and we speculate that using a more restrictive measure of 'very active' workers decreases this figure to 15,000 . This analysis contributes to research on platform labour and the labour in the digital economy that lies behind artificial intelligence.

Keywords: Micro-work, digital platforms, labour statistics

\section{This is a pre-print version of:}

Paola Tubaro, Clément Le Ludec, and Antonio A. Casilli (2020). Counting 'micro-workers': societal and methodological challenges around new forms of labour. Work Organisation, Labour \& Globalisation 14, no. 1, pp. 67-82, doi:10.13169/workorgalaboglob.14.1.0067 


\section{Introduction}

Micro-work is the most elusive form of labour in the digital economy. Specialised platforms like Amazon Mechanical Turk 'unbundle' (Pesole, Urzì-Brancati, Fernández-Macías \& González-Vázquez, 2018) larger work packages into tiny 'tasks' that they make available to myriad, largely anonymous providers who execute them online. Examples of such tasks include detecting or labelling objects on images, transcribing invoices, translating fragments of text, classifying videos, sorting or ranking photographs and recording utterances. Standardised and repetitive, these tasks typically take only a few minutes, require limited skills, are paid on a piecework basis and attract compensation that can be as low as a few cents per task. By mobilising many micro-workers simultaneously for a few hours rather than a single subcontractor for a longer time, platforms (and their clients) conjugate process scalability, workforce flexibility and cost effectiveness.

A by-product of today's 'datafied' economy (Mayer-Schönberger \& Cukier, 2013), micro-work supports the digital transformation of companies: for example, transcription of scanned invoices may serve the creation of a paperless archive. More prominently, micro-work feeds into the scientific and industrial development of artificial intelligence (Gray \& Suri, 2017). Labels that identify objects in natural settings can be used to train machine learning models. For instance, labelled images of cars in road traffic are necessary for the operation of autonomous vehicles (Schmidt, 2019; Tubaro \& Casilli, 2019), conversation transcripts help improve automatic speech recognition for smart speakers, and sets of predefined questions and answers can be used to develop virtual assistants (Casilli et al., 2019).

The current blossoming of artificial intelligence and other data-intensive production processes suggests that there might be a large, and possibly growing, market for micro-work services. Its expansion may be part of a broader trend, insofar as the global volume of all 'online labour' - an expression which primarily encompasses the highly qualified online freelancing work of professionals such as graphic designers and software developers - increased by a whopping 25\% between 2016 and 2018 (Kässi \& Lehdonvirta, 2018). However, the size of the micro-workforce itself is very difficult to estimate. Micro-work is more likely than other platform-based earning activities to be underreported in general social surveys. The simple, short and sometimes 'gamified' nature of micro-tasks misleads workers who often fail even to recognise them as labour. Even those who do are unlikely to report these tasks if they are secondary or occasional activities, especially in studies - such as Labour Force Surveys - that focus on peoples' main, stable occupation. Much more helpful are ad-hoc research initiatives that attempt to estimate the number of platform workers in general, but they do not specifically target micro-work, and can only provide indirect clues. For example, results for France of a major European comparative survey (Huws, Spencer, Coates \& Holts, 2019) indicate that $3.8 \%$ of the adult population, amounting to about 2 million people, does online clerical work, small tasks and 'click-work' - a set of activities that is broader than micro-work as we defined it above, but includes most of it, and can thus be loosely taken as an upper boundary. A literature with specific focus on micro-work exists but is still in its infancy, and has been primarily qualitative so far (Gray \& Suri, 2019; Irani, 2015; Schmidt, 2019).

In the absence of sufficiently precise survey data, many studies have simply chosen to rely on the information that (some) platforms release publicly about their user base. If Amazon Mechanical Turk boasted 500,000 members as early as 2014 (Harris, 2014), at about the same time the Chinese giant Witmart was said to have several million. An influential 2015 World Bank report summed the number 
of registered users across the main international platforms then known (mainly Mechanical Turk and Crowdflower ${ }^{1}$ ), arriving at an estimate of 5.8 million people worldwide (Kuek et al., 2015).

At the time of writing, figures like these remain the best guess of the size of the micro-working market. However, they are likely an overestimate, and fail to answer the question of how many people micro-work in a given country - the question that policy-makers are most likely to need answered. To shift emphasis from a platform - which typically operates internationally - to a country - where several platforms may coexist - requires a set of steps to progressively bring down the platforms' figures to more realistic levels. We need to map the various platforms that operate in the country of interest, and aggregate their numbers in ways that exclude non-residents and avoid double counts (which may occur if workers register with multiple platforms). Finally, we should distinguish between the number of sign-ups and the number of actually active workers. Because micro-work is often supplementary to other occupations, the latter will be lower than the former by differing degrees depending on how activity is defined.

To the best of our knowledge, no attempt has been made so far to estimate the number of microworkers in a specific country across micro-work platforms, considering multiple uses and levels of engagement. As a first step toward filling this gap, this article endeavours to do so in the case of France. A heavy investor in artificial intelligence research, France is little documented in the (still scant) literature on micro-work, and its residents are relatively less present on international platforms such as Amazon Mechanical Turk. Partly for linguistic reasons, France has its own microwork platforms, the most popular of which is Foule Factory ${ }^{2}$, whose webpage displays 50,000 contributors.

In this article, we present a series of experiments that leverage a mix of methods to adjust downwards the figures released by platforms. We make a case for going beyond the most renowned platforms and looking at local conditions in addition to global trends. We reflect on the limitations of this exercise, which, due to definitional uncertainties and platforms' lack of transparency, can at best aspire to provide orders of magnitude, rather than exact figures. We conclude with recommendations for constructive ways forward that build on the lessons learned from our research.

\section{The challenges of measuring micro-work}

Micro-work does not fit neatly into the categories ordinarily used to measure the labour force. In what follows, we present insights from existing studies and discuss the difficulties that they raise.

\section{Why surveys and administrative data fail to detect micro-work}

Official statistical surveys are usually designed to report the main occupation of respondents, while the flexibility afforded by online platforms allows arranging work as a secondary activity, to earn a supplement of income. Unsurprisingly, then, studies such as that of Katz \& Krueger (2019), which follow standard statistics in tracing only people who perform platform work as a main job, obtain low estimates $(0.5 \%$ of the adult population). Labour Force Surveys also miss people who perform platform work irregularly, because they assume that those who answer 'yes' to the question of

\footnotetext{
${ }^{1}$ Crowdflower was later re-branded as Figure Eight and was acquired by another industry leader, Appen, in 2019.

2 'Foule' is the French for 'Crowd'. Foule Factory has recently re-branded as a set of two sister companies: Yappers.club, the micro-working platform, and Wirk.io, which sells artificial intelligence solutions to companies.
} 
whether they did any paid work in a given reference period did so with some regularity. To measure platform work, then, we cannot be content with classical survey questions and also need to assess regularity, intensity and significance (Urzì-Brancati, Pesole \& Fernández-Macías, 2019). These issues are common to many forms of platform labour (from transportation and delivery to software development), but are amplified when large data jobs are fragmented into tiny tasks in microwork.

While the language and structure of official statistical agencies is slowly adapting to the fast-moving world of the platform economy, several groups of academic researchers, unions and think-tanks have attempted to launch smaller, dedicated surveys at country or cross-country levels (O'Farrel \& Montagnier, 2019). Although, as mentioned above, they did not specifically target micro-workers, they enable some indirect guesstimates. The COLLEEM survey, carried out in 14 European countries in 2017, reckons that slightly fewer than $10 \%$ of people aged 16-74 years have ever done any platform work (Pesole, Urzì-Brancati, Fernández-Macías \& González-Vázquez, 2018), with differences across countries (12.5\% in Spain, $7.6 \%$ in France). Of these, $24.7 \%$ are said to have performed microtasks at least sporadically (Urzì-Brancati, Pesole \& Fernández-Macías, 2019) ${ }^{3}$. These ratios would result in about 900,000 micro-workers in France - but this might be an over-estimate as about half of COLLEEM respondents perform varied platform tasks, and micro-work may be just one of them.

While these surveys are valuable tools to situate micro-work in the broader context of platform work more generally, differences in how they operationalise the notions of secondary and irregular activity produce widely divergent results. For example, the COLLEEM survey produced systematically higher values than a comparable one, the 2018 Eurobarometer (O'Farrel \& Montagnier, 2019:14) ${ }^{4}$. Depending on their design, extant estimates of the extent of platform work (of which micro-work is one part) range from $0.4 \%$ to $22 \%$ of the size of Western economies (Frenken, 2018), although many are in the range of about $0.5 \%$ to $2 \%$ (O'Farrel \& Montagnier, 2019).

Administrative data might in principle compensate for the limitations of surveys, for example if the fiscal authorities required platforms to report users' earnings for tax collection purposes. Nevertheless, micro-workers earn very little (the lowest hourly rate among all platform workers according to Urzì Brancati, Pesole \& Férnandéz-Macías, 2020:38), so that their platform incomes would fall below the given tax thresholds, and their activity would go under-reported.

\section{The data reported by micro-work companies are registrations}

Most micro-tasking platforms release information about their user base publicly. There is a clear incentive for them to report the number of those who open an account, which generates value insofar as 'it gives the appearance that the platform has a lot of labour on standby for those trying to find workers to fill a project need' (Gray \& Suri, 2019:104).

But even platforms that provide such figures rarely give the breakdown of the number of registered workers by country. This is because micro-work is geographically 'un-sticky' (Ojanperä et al., 2017), executed remotely, potentially from anywhere. Even when platforms effectively monitor workers'

\footnotetext{
${ }^{3}$ The COLLEEM II survey of 2018 showed a slight increase in platform work throughout Europe (with relative stability in France compared to other countries), with an overall increase among platform workers who do micro-tasks (Urzì-Brancati, Pesole \& Férnandéz-Macías, 2020).

${ }^{4}$ The Flash Eurobarometer 467 'The use of the collaborative economy', 2018, estimates that $11 \%$ of the adult French population have offered services through platforms. $5 \%$ of them (about 300,000 people) have performed online services such as IT and accounting, while 7\% (about 420,000) have offered 'other' online services: neither category corresponds precisely to micro-work, but both cover parts of it.
} 
residence, for example by requiring formal proof of ID at registration, they typically prefer to showcase their large, global reservoir as a whole. In this way, they expose micro-workers to broad competition, producing an over-supply of labour, as already documented in the case of qualified freelancing (Graham \& Anwar, 2019), and keep remunerations low, in the interest of clients.

\section{Challenging the platforms' figures}

Some studies set out explicitly to probe the publicly announced company data, specifically the 500,000 'Turkers' announced by Amazon Mechanical Turk, the oldest and by far the most famous platform. A key motivation of many of these studies is to assure the quality of the results of scientific surveys, questionnaires and experiments for which research teams in disciplines such as psychology, marketing, and linguistics recruit Turkers (Fort, Adda \& Cohen, 2011). This involves ensuring access to a sufficiently large pool of respondents to guarantee a robust sample (Keith, Tay \& Harms, 2017). In this perspective, Stewart et al. (2015) borrowed the bio-ecological 'capture-recapture' model to show the existence of a pool of 7,300 potential study participants on Mechanical Turk. At about the same time, activist Kristy Milland (2017) conducted a six-week survey and counted about 30,000 workers. These lower figures throw suspicion on Amazon's figures, but they might be severe underestimates of the platform's population. Difallah, Filatova \& Ipeirotis (2018) criticised Stewart's model for its assumption that workers are equally likely to undertake tasks. Taking into account individuals' heterogeneity, they showed that over 100,000 people work on this platform. This is less than the advertised population, but almost fourteen times as many as Stewart et al. (2015) claimed. A more recent study gets even closer to Amazon's own figures, finding 250,000 Turkers worldwide using data from TurkPrimer, an independent company that helps researchers design and implement studies on Mechanical Turk (Robinson, Rosenzweig, Moss \& Litman, 2019).

No other platform has been scrutinised in such detail, and these studies differ from what we intend to do because they focus on a platform across countries, rather than a country across platforms although 75\% of Amazon Mechanical Turk workers are Americans (Difallah, Filatova \& Ipeirotis 2018). Nevertheless, they have broader implications in that they show that counting micro-workers on a platform can be based on differing definitions, leading to differing outcomes. The sheer number of sign-ups that platforms report does not correspond to the actual pool of workers a client may tap into for a specific project at a given point in time. Diversity in workers' engagement, and the platform's own functioning rules (which may for example select which workers access which tasks, thereby producing fluctuations in the actual size of its workforce), explain the widely diverging results obtained in this literature.

\section{Registered vs 'active' micro-workers}

The above discussion suggests that there is a need to characterise in more detail the notion of 'active' workers, relative to those who just sign up to one or more platforms. Urzi-Brancati, Pesole and Férnandéz-Macías (2020), who study platform work in general and not specifically micro-work, distinguish four categories, the 'sporadic', 'marginal', 'secondary' and 'main' platform workers, depending on a combination of frequency, hours and income generated. Focusing specifically on micro-work, Gray and Suri (2019:104-105) distinguish three groups, the 'experimentalists' who come to a platform but leave shortly thereafter, the 'regulars' who work intermittently, and the 'always-on' who turn micro-work into the online equivalent of full-time jobs. Most people start out as experimentalists and may evolve into one of the other two categories. 
Insight from fieldwork suggests that these differences hold in France too. In 2018, we distributed an online questionnaire through the online micro-tasking platform Foule Factory, collecting 908 unique, fully usable responses, and we interviewed in depth 92 workers, clients and platform owners. We met micro-workers who did tasks every day, even if not always full-time - such as a nurse, who used all her breaks to perform 'simple and quick tasks' online. Other respondents worked less frequently but regularly. An editorial manager in a communication agency signed up at a time when her 'lifestyle required an additional income', resulting in 'a compulsive need to earn more money'. She continued to micro-work later, though not with the same intensity as before, mostly to do paid questionnaires which constitute her preferred task. Other study participants had a more intermittent approach to micro-work. One respondent, holding a day-job as administrative secretary, 'quickly dropped out' after registering, but resumed activity later in a relatively sustained way, after a reminder email from the platform. Another, seeking employment at the time of the interview, alternated phases of inactivity and of intense engagement, depending on her employment status. When jobless, she micro-worked very hard because she preferred to 'do this rather than nothing'.

\section{Three ways to estimate the number of micro-workers in a country}

We now bring forward this discussion in the case of the French micro-working population. We start by identifying the micro-tasking platforms that recruit French workers. Then we take the figures publicly provided by these platforms, and test methods to correct them downward.

\section{What micro-work platforms operate in France?}

We decided not to limit our investigation to Amazon Mechanical Turk, where demand from French companies outweighs the supply of French micro-workers. The platform's payment arrangements discourage registrations outside the USA and, to a lesser extent, India. Recent research (Berg et al., 2018; Forde et al., 2017) covering multiple countries including France, has added more platforms Crowdflower (later rebranded Figure Eight), Microworkers, Clickworker and, in the case of Berg et al. (2018), Prolific. We included their selection of platforms except for Prolific, a site that specialises in surveys that exists only in English, and which, according to Berg et al. (2018) has no users in France. We also retained ClixSense, which provides access to Figure Eight, and Appen, the company that recently acquired Figure Eight. Appen is an international platform open to recruitment in France, which lists tasks of the same nature as the others, but has a tighter and more closed business model that enables it to manage large orders for clients, and to offer more regular assignments to workers.

In addition to these international platforms, we included Foule Factory (now Yappers.club/Wirk.io), which exclusively recruits its micro-workers in France and, since its creation in 2014, has established itself as a key player in the market. We also added Ferpection, a French platform that recruits nationally and internationally. These platforms are potentially more attractive for French users than others, such as Microworkers, whose sign-up form is only available in English.

We excluded from our scope platforms for qualified freelancing projects such as Malt and Upwork, which specialise in longer 'missions' rather than disassembled, tiny tasks. These platforms offer qualitatively different services and adopt a different business model, although some freelancers (for example, translators) may also do some micro-work. We also left out income-generating mobile applications such as BeMyEye and Roamler, which do offer micro-tasks, but of a type that requires physical presence in a given place (for example, taking pictures of products in supermarkets). Finally, we excluded other international micro-tasking websites and applications, such as CrowdGuru and 
Spare5, which may recruit French workers but seem to be very rarely used in the country, and would therefore add little to our count of micro-workers. By 'rarely', we mean that they were not mentioned by any of our study respondents, and there was no more than one occurrence in discussions on Net Business Rating, the country's largest discussion forum on online earning opportunities (now rebranded as Foxy Rating), which has hosted more than 150,000 messages over nine years. Two platforms that fell just above this threshold, Lionbridge and Pactera, had, unfortunately, to be excluded due to lack of data.

\section{Analysing public data available from platforms}

The first column in Table 1 presents the figures provided by our selection of platforms. There are differences that depend on whether the scope of the platforms is international or national, and on their registration policies: while anyone can sign up to Clickworker or ClixSense in a few simple steps, Appen screens potential new micro-workers through a full-fledged application process, and Foule Factory closed its registrations after a peak, created a waiting list, and put in place a deregistration policy for inactive users. Platforms also differ in their degree of precision: while Microworkers gives very detailed and up-to-date figures, others just provide approximations, and Amazon has never changed its count of 500,000 advertised a few years ago (and has even removed it from its website).

Regarding breakdowns by country, only gross approximations are available. The German platform Clickworker (2018) says that France and other European countries (excluding Germany) account for $25 \%$ of its workforce ${ }^{5}$. ClixSense and Appen provide no details, and French platforms differ: while Foule Factory is only accessible to residents of France, Ferpection has users signing up from France, the United Kingdom, the United States, Ireland and other countries ${ }^{6}$. Regarding the other two platforms, the only hints are from researchers. French workers constitute a small fraction of Mechanical Turk's user base (Difallah, Filatova \& Ipeirotis, 2018). On Microworkers, France is among the group of countries where less than $20 \%$ of total transactions occur (Hirth, Hoßfeld \& Tran-Gia 2011).

\section{Analysing experimental data with the 'capture-recapture' model}

To challenge Amazon's publicly available data, Stewart et al. (2015) and Difallah, Filatova \& Ipeirotis (2018) implemented a 'capture-recapture' experiment on Mechanical Turk. Having posted a microtask for a relatively long period of time, and allowing repeated participation, the technique consists in 'capturing' participants a first time, identifying them as having already done the task, then seeing how many of them get 'recaptured' a second time.

We replicated this approach on the French leading micro-working platform Foule Factory where we distributed our questionnaire. We did so in two steps over two months: the first phase obtained 505 valid responses and the second 492. While mere logistical issues motivated this two-step collection, we saw it as an opportunity to estimate the number of micro-workers on Foule Factory. In the second phase, we detected 89 returning respondents - enabling use of the capture-recapture model.

\footnotetext{
${ }^{5}$ See https://www.clickworker.com/about-us/clickworker-crowd/accessed on December 3, 2018.

6 See http://help.ferpection.com/l/fr/les-utilisateurs/combien-y-a-t-il-dutilisateurs-dans-la-communaute accessed on December 3, 2018.
} 
Two assumptions are made in the capture-recapture model: first, the population is closed (that is, nobody entered or left the platform during the study); and second, all subjects have the same chance of being captured. The former was satisfied in our case, as Foule Factory's closed-registration policy and the short time interval between the two waves limited the number of those entering or exiting. The so-called Lincoln-Petersen formula applied to the data thus collected, with $N$ being the total number to be estimated, $n_{1}$ the number of users captured in the first wave, $n_{2}$ the number in the second wave and $m$ the number of recaptured participants, gives:

$$
N=\frac{n_{1} n_{2}}{m}
$$

Based on the number of individuals observed, the result of this calculation gives a population of 2,792 micro-workers. This is only $5.6 \%$ of the platform's public declaration of the size of its workforce $(50,000)$ but is consistent with the experience of its managers who were confident that 'over two months, [we] can mobilise up to 3,000 people on this type of task'. This figure is relatively high compared to the estimate of 7,300 that Stewart et al. (2015) obtained with the same method for Amazon Mechanical Turk, corresponding to $1.5 \%$ of the platform's alleged 500,000 users.

However, this is likely an underestimation. The second assumption of the model (equal chance of capture) does not hold if users display an uneven level of involvement in micro-work on Foule Factory. Facing the same issue on Amazon Mechanical Turk, Difallah, Filatova \& Ipeirotis (2018:141) introduce a latent variable $a$ that they interpret as propensity to participate, reflecting the fact that some people perform any tasks available on the platform, while others choose tasks more selectively. The formula becomes:

$$
N^{*}=\frac{n_{1} n_{2}}{m}\left(1+\frac{\operatorname{Var}(a)}{E(a)^{2}}\right)=N\left(1+\frac{\operatorname{Var}(a)}{E(a)^{2}}\right)
$$

Clearly, $N \approx N^{*}$ when $\operatorname{Var}(a)$ is small, but $N<N^{*}$ otherwise, and the underestimate is more severe when the variance is higher. Our two observations do not suffice to estimate the distribution of $a$ (Difallah, Filatova \& Ipeirotis, 2018), but other information from our questionnaire points to differences in micro-workers' propensity to do tasks. The great majority $(62 \%)$ did up to three tasks in the month before our survey, $21 \%$ did four to six tasks, and a thick tail of $17 \%$ did more than six. If these differences are comparable to those observed among Mechanical Turk workers, then our capture-recapture result is insufficient to invalidate Foule Factory's declaration of 50,000 microworkers - just as Difallah, Filatova \& Ipeirotis (2018) confirm Amazon's claim that 'the MTurk platform does provide access to hundreds of thousands of workers'.

Another reason why this approach is of limited help to answer our research question is that it is designed to count workers on a platform, not on a set of platforms operating in the same country. It was relatively easy to apply it on Foule Factory, but the international scope of the other platforms in our sample would make it difficult to restrict 'capture' to French workers. 


\section{Analysing web traffic data to measure the audience of micro-work platforms}

We borrowed from media studies a method that relies on user panels to measure the audience of micro-working platforms. We used the service SimilarWeb.com ${ }^{7}$, which counts the number of unique monthly visitors to these sites worldwide (see Table 1, columns 2-4).

To use this source, we had to rule out the possibility of double counting, which might occur if, for example, the same person connected via different devices or IP addresses. SimilarWeb controls for this to the extent that it tracks panel members through an app that they must install on their device. In addition, responses to our questionnaire indicated that micro-workers use their own devices (99\% have their own laptop and/or desktop; $89 \%$ have a smartphone) and are unlikely to vary their modes of connection ( $79 \%$ of them always connect through their home broadband, $13 \%$ through their mobile phone data plan, and only $8 \%$ use public Wi-Fi or variable solutions). It was also necessary to exclude non-workers, notably clients. This is easily achieved as most platforms have separate web interfaces for client companies and for micro-workers, so we focused exclusively on the latter (for example, Fouleurs.com, now Yappers.club, for Foule Factory). Additionally, some users of pages such as Fouleurs.com may be simple visitors - such as journalists or researchers like us. To ensure that the great majority were workers, we looked at the average duration of visits. Most of these pages display very little content (if at all) before login, and non-registered viewers are unlikely to spend time there. The relative length of visit durations (Table 1, column 3) suggests that these pages are mostly accessed by micro-workers who log in. SimilarWeb figures (column 2) are lower than the number of registrations reported by platforms (column 1), except for Amazon Mechanical Turk.

Let us now comment especially on the fourth column of Table 1, which reports the average number of French unique monthly visitors per platform. Starting with Foule Factory, we observed 6,958 unique micro-workers accessing it on average every month. This can thus be interpreted as the size of the active population on this platform over a month (as could be measured in the summer of 2018). Almost all visits originated from France, in accordance with the platform's policy. The residual cases of people signing in from outside France essentially concern French micro-workers temporarily connecting from abroad - as also found in our questionnaire. Concerning the other micro-work platforms offering access interfaces in French, ClixSense, Clickworker, Appen and Ferpection are more visited than Foule Factory. This may be due to open registration policies (for example Clickworker) and/or lifespan (for example ClixSense, which was created in 2009). Some also benefit from their role as gateways to other micro-work platforms: as noted above, ClixSense gives access to Crowdflower, while Clickworker is a pathway to UHRS, Microsoft's proprietary micro-working service.

SimilarWeb did not publish the number of French micro-workers on Amazon Mechanical Turk because of its policy of concealing figures that it considers too low. Thus, the total number of worldwide users of this platform may have grown since the company claimed that there were 500,000 such workers but this was not the case in our country of interest, at least in terms of monthly usage.

Audience figures have the advantage of providing a measure of workers' activity, beyond the simple fact of registration, in a well-defined sense. Column 4 of Table 1 reports the average monthly number of unique visitors from France, calculated over three months, and its sum across platforms. This method mainly represents users who connect at least monthly - indeed any more frequent activity

\footnotetext{
${ }^{7}$ The data used by SimilarWeb.com come from two main sources: partnerships that the site has established with Internet service providers and data that the site retrieves with an add-on to users' internet browsers - which provides users with metrics of website traffic in exchange for their browsing data.
} 
would not change the total and, conversely, more sporadic connections are less likely to be counted at all. Thus, we can take this measure as an estimate of the number of micro-workers who are not just registered but have at least a 'regular' (here, monthly) level of activity. For most of them, this most likely involves using micro-work as a secondary, but stable, source of income.

Interestingly, audience figures enable an assessment of the number of registered micro-workers who are located in France. To compute their number, we need to infer their frequency of connection to the platforms as a percentage of the total number of persons signed up worldwide. Column 5 of Table 1 reports the results of these calculations. For Amazon Mechanical Turk, given the lack of audience figures, we used a survey conducted by a New York University team ${ }^{8}$. Extrapolating from the size of the group of French 'Turkers' that they observed, i.e. $0.25 \%$ of the total, assuming that their sample is representative, and taking conservatively the 500,000 total as a reference, we estimate that around 1,250 French residents operate on this platform.

\section{Accounting for users who micro-work on several platforms}

We have tested different ways to bring down the number of signed-up users (over 11 million individuals worldwide), which is itself to be seen as an order of magnitude rather than a precise computation, insofar as most platforms provide only approximate figures. The capture-recapture model previously used in the literature counts little fewer than 3,000 individuals in a single national platform, Foule Factory, but is a potentially severe underestimate, and can hardly be generalised to the sample as a whole. The audience-based measure provides an intermediate estimate of little more than 60,000 individuals across platforms all over France, and can be taken as a measure of activity, interpreted as monthly (at least) connection to the platform. If the proportion of French residents among all monthly users is the same as their proportion among all registered users, then we can infer that there are over 300,000 French registrations on the seven platforms in our sample.

An additional correction is now needed to take into account workers performing micro-tasks on several platforms. As noted above, disregarding multi-activity amounts to counting the same persons multiple times. How many platforms do people use at the same time? To answer this question, we turn to our survey, in which participants were asked to indicate their use of different micro-work platforms from a list of options. $16.6 \%$ of them used at least two platforms from among those included in our sample, which amounts to saying that, on average, each person uses 1.27 microtasking platforms. The question referred to actual use, not just awareness of, each of these platforms.

Assuming that our sample is representative and extrapolating its behaviour to the entire French micro-working population amounts to applying this rate to the measures previously obtained. Once this has been done, the intermediate estimate of monthly active workers goes down to about 50,000 , and the count of registrations approaches 260,000 .

\section{Discussion: strengths and limitations of present methods}

The methods we have deployed are a journey into uncharted territory, aiming to assess the size of a workforce that escapes the definitions and measurements of official statistics and even, to some

\footnotetext{
${ }^{8}$ Data from the survey 'Analyzing MTurk demographics' are available at https://github.com/ipeirotis/mturk_demographics and are used in Difallah, Filatova \& Ipeirotis (2018).
} 
extent, ad hoc surveys. Following statistical practice, we have taken one country rather than one platform as our basic unit of observation. We have accounted for: the specificities of micro-work, notably diversity in levels of engagement, with many people practising it as a secondary or infrequent activity; absence of geographical anchor, which implies co-existence of both national and international platforms; and simultaneous use of multiple platforms. Our choice of methods borrows from the methodological literature on Mechanical Turk (the capture-recapture model) and from neighbouring fields (web traffic measures) to correct publicly-available data from companies.

\section{Methodological limitations}

Throughout this journey, we have had to make some strong assumptions and simplifications. We have taken a larger sample of platforms than any existing quantitative studies of micro-work, but lack of data prevents exhaustiveness. The capture-recapture method is only helpful for studying a single platform, not a country whose workers may participate in multiple platforms. It is a complex method whose application to Amazon Mechanical Turk has led to widely divergent results. We could not use it confidently except on the single French-only platform in our sample, Foule Factory, which resulted in obtaining a downward-biased result. Because the method is more likely to over-sample users with a high propensity to complete tasks, this result might be loosely seen as an approximate measure of the number of 'very active' users on this platform, defining activity as the likelihood to complete a task. We innovated in using audience panels to measure the number of active users along another dimension - their minimum frequency of connection over a given time frame (monthly in our case). Thus, we can interpret the result as a count of 'regular' users. However, these measures are built by private companies for business purposes, with limited scope for researchers to control their quality. On occasions, we used data from our Foule Factory survey to refine all these measures (for example, to account for multi-activity), which required the assumption that our sample is representative of the whole French micro-working population.

For all these reasons, our figures should be interpreted as orders of magnitude rather than exact amounts: we retain about 50,000 'regular' and 260,000 registered micro-workers. Other definitions of activity can be expected to further lower these figures, as is the case for Foule Factory, which has less than 3,000 'very active', over 6,000 'regular' and 50,000 registered workers. We could even speculate that, if the same ratio of 'very active' to registered workers were the same on all other platforms in our sample, we would count about 15,000 'very active' micro-workers throughout the country. Because these figures have been obtained through different methods, they cannot meaningfully be added; neither can they be construed as subsets of one another, the 'very active' constituting an inner circle and the registered an outer circle, with the 'regular' in-between. These labels only indicate the levels of engagement that each of these methods over-represents compared to the others.

\section{Why our methods are nevertheless helpful}

Despite these limitations, these figures provide helpful indicators for research and policy. The 50,000 includes people who micro-work frequently enough, but not necessarily very frequently. The volume of economic activity that these workers generate is presumably small, but not negligible. Use of platforms for extra income rather than a main job is not unique to micro-work, and has already been observed in surveys of platform labour in general (Huws, Spencer, Coates \& Holts, 2019). Regarding micro-work specifically, this usage may be specific to Europe and North America, with providers in 
low-income and emerging countries choosing more often to micro-work full-time to meet growing demand by large digital companies (Gray \& Suri, 2019; Schmidt, 2019). In countries such as France, the need for an extra source of income that the existence of these workers brings to light calls for a better understanding of the conditions under which it emerges: what are the unmet needs that push people to seek additional earnings through micro-work?

The 260,000 figure corresponds to the number of French users registered on one or more of the seven micro-tasking platforms we considered. This might seem a surprisingly large number, especially for a type of platform work that has attracted limited public attention so far. However, it is the same order of magnitude as the estimate of about 300,000 that might be derived from the 2018 Eurobarometer, and it is lower than the 900,000 of the European COLLEEM I survey discussed above - although these comparisons are only loosely indicative because definitions vary across studies. Also, its full-time equivalent may be very small, because many of these 260,000 do few tasks. The real question is what this count of 260,000 represents - before comparing it to data obtained with different methods, or converting it into categories alien to the platform economy.

We contend that this very figure has strong implications for both theory and policy. Like the freelancers studied by Graham \& Anwar (2019), these micro-workers constitute a large pool of labour power that platforms can advertise to attract clients. In two-sided markets such as these, higher numbers on one side (micro-workers) attract participation on the other side (clients) to the benefit of the platform (which typically charges fees to clients). Even with variable levels of activity on the part of workers, platforms can leverage their sheer numbers of sign-ups to gain clients and collect the fees that they pay, in a virtuous (for them) circle. Large numbers of registered workers are also a resource that, though partly inactive most of the time, clients may tap into whenever their data needs become more pressing. When needed, platforms reach out to idle workers to invite them to resume their activity - which they may well do, as in the case of one of our interviewees cited above. To meet the (sometimes large) peaks in companies' demand, platforms make this human workforce available in amounts that are huge and at times excessive. Endemic to all forms of online labour, this massive excess supply shifts the power balance toward platforms (and clients), pushing remunerations down to the detriment of workers.

\section{Concluding remarks}

A final thought before concluding brings us back to surveys and how they differ from our exercise. We do not intend to challenge surveys, which remain a most-needed instrument to gain insight into the current transformations that affect our societies. But we address the question of how many residents of a country operate on its micro-working platforms, while surveys ask how many do platform work (including, but not limited to micro tasks). Our different question stems from a broader interrogation of the size of the market for services for the artificial intelligence and other data-intensive industries. Compared to surveys, it requires digging more deeply into the world of platforms, notably with detailed upfront scoping requiring an inventory of relevant platforms.

These approaches provide different perspectives that can inform labour policies. The need for a mix of methods is all the more acute as in the data economy that thrives through platforms, parts of the world of work escape established definitions and miss the gaze of official statistics, gradually sliding into invisibility. Ad hoc surveys (and inclusion of targeted questions into general surveys) raise awareness among respondents and final users, while approaches like ours that elaborate on companies' declarations and trace workers' connections provide a view of actors' practices. Both contribute to the broader reflection on how to give visibility to these new forms of labour. 
The methods we implement provide insight for future questionnaire designers by demonstrating the importance of including smaller and lesser-known platforms. The examples often proposed in survey questions ('have you done activities... on platforms such as Amazon Mechanical Turk') should not be limited to the most renowned cases, or they may mislead respondents who micro-work for local or less mediatised platforms. The case of France is illustrative of the importance that national actors like Foule Factory and Ferpection may have.

Surely, there is scope for improvement. Collaborations with platforms may help verifying registration figures, and implementing tools to monitor activity and turnover. Audience panels would prove their full potential if they allowed following connections over a long time - and if they were more transparent as to the details of their calculations. So far, few platforms and audience measure companies have been so open to allow detailed research - Mechanical Turk being one of them. In most cases, these companies rely on this information as an economic resource in a highly competitive environment, and are unlikely to open themselves further. Behind statistical measures, it is the broader question of corporate power that takes centre stage in the digital economy.

(C) Paola Tubaro, Clément Le Ludec and Antonio A. Casilli, 2020 


\section{References}

Berg, J., M. Furrer, E. Harmon, U. Rani, \& S.M. Silberman (2018), Digital Labour Platforms and the Future of Work: Towards Decent Work in the Online World, Geneva: ILO Report.

Casilli, A.A., P. Tubaro, C. Le Ludec, M. Coville, M. Besenval, T. Mouhtare, \& E. Wahal (2019) Le microtravail en France. Derrière l'automatisation, de nouvelles précarités au travail? Report of the Digital Platform Labor (DiPLab) project, iplab.eu/wp-content/uploads/2019/05/Le-Micro-Travail-EnFrance_DiPLab-2019.pdf

Difallah, D., E. Filatova \& P. Ipeirotis (2018) 'Demographics and dynamics of Mechanical Turk workers', Proceedings of WSDM 2018: the Eleventh ACM International Conference on Web Search and Data Mining, ACM:135-143.

Forde, C., M. Stuart, S. Joyce, L. Oliver, D. Valizade, G. Alberti, K. Hardy, V. Trappmann, C. Umney \& C. Carson (2017) The Social Protection of Workers in the Collaborative Economy, Report for the Committee for Employment and Social Affairs, Strasbourg: European Parliament.

Fort, K., G. Adda \& K. Cohen (2011) 'Last words: Amazon Mechanical Turk: Gold mine or coal mine?' Computational Linguistics, 37(2):413-420.

Frenken, K. (2018) 'Unpacking the gig economy - are we asking the right questions?', Reshaping Work 2018 Conference, Amsterdam, October 25-26.

Graham, M. \& M. Anwar (2019) 'The global gig economy: Towards a planetary labour market?' First Monday, 24(4), URL: https://firstmonday.org/ojs/index.php/fm/article/download/9913/7748.

Gray, M.L. \& S. Suri, S (2017) 'The humans working behind the Al curtain', Harvard Business Review, (9):2-5.

Gray, M.L. \& S. Suri (2019) Ghost Work: How to Stop Silicon Valley from Building a New Global Underclass, Boston, MA: Houghton Mifflin Harcourt.

Harris, M. (2014) ‘Amazon's Mechanical Turk workers protest: “I am a human being, not an algorithm"', The Guardian, December 3.

Hirth, M., T. Hoßfeld \& P. Tran-Gia (2011) 'Anatomy of a crowdsourcing platform - using the example of Microworkers.com', Proceedings of the 2011 Fifth International Conference on Innovative Mobile and Internet Services in Ubiquitous Computing:322-329.

Huws, U., N. Spencer, M. Coates \& K. Holts (2019) The Platformisation of Work in Europe: Results from Research in 13 European Countries, Commissioned report, Brussels: Foundation for European Progressive Studies.

Irani, L. (2015) 'The cultural work of microwork', New Media \& Society, 17(5):720-739.

Kässi, O. \& V. Lehdonvirta (2018) 'Online Labour Index: Measuring the online gig economy for policy and research', Technological Forecasting and Social Change, 137:241-248.

Katz, L. \& A. Krueger (2019) 'The rise and nature of alternative work arrangements in the United States, 1995-2015', ILR Review, 72(2):382-416.

Keith, M., L. Tay \& P. Harms (2017) 'Systems perspective of Amazon Mechanical Turk for organizational research: review and recommendations', Frontiers in Psychology, (8):1359. 
Kuek, S., C. Paradi-Guilford, T. Fayomi, S. Imaizumi \& P. Ipeirotis (2015) The Global Opportunity in Online Outsourcing, Report, Washington DC: The World Bank.

Mayer-Schönberger, V. \& K. Cukier (2013) Big Data: A Revolution that Will Transform How We Live, Work, and Think, Boston, MA: Houghton Mifflin Harcourt.

Milland, K. (2017) '150717 Preliminary results - Mapping study'. Accessed November 5, 2019, from https://docs.google.com/spreadsheets/d/1T3yP_Jo4qELrwsE2NAPNs07L1AWmpAEr9vnhreGJ-

Ko/edit\#gid=1993074859.

O'Farrel, R. \& P. Montagnier (2019) 'Measuring platform mediated workers', OECD Digital Economy Papers, n. 282, Paris: OECD.

Ojanperä, S., M. Graham, R. Straumann, S. De Sabbata \& M. Zook (2017), 'Engagement in the knowledge economy: Regional patterns of content creation with a focus on Sub-Saharan Africa', Information Technologies and International Development, (13):33-51.

Pesole, A., C. Urzì-Brancati, E. Fernández-Macías \& I. González-Vázquez (2018) Platform Workers in Europe: Evidence from the COLLEEM Survey, Report EUR 29275 EN, Brussels: Publications Office of the European Union, JRC112157.

Robinson, J., C. Rosenzweig, A. Moss \& L. Litman (2019) 'Tapped out or barely tapped? Recommendations for how to harness the vast and largely unused potential of the Mechanical Turk participant pool', PsyArXiv preprint, doi:org/10.31234/osf.io/jq589.

Schmidt, F. (2019) Crowdproduktion von Trainingsdaten: Zur Rolle von Online-Arbeit beim Trainieren autonomer Fahrzeuge. Report, Berlin: Hans-Böckler-Stiftung.

Stewart, N., C. Ungemach, A. Harris, D. Bartels, B. Newell, G. Paolacci \& J. Chandler (2015) 'The average laboratory samples a population of 7,300 Amazon Mechanical Turk workers', Judgment and Decision Making, 10(5):479-491.

Tubaro, P., \& A.A. Casilli (2019) Micro-work, artificial intelligence and the automotive industry. Journal of Industrial and Business Economics, 46(3): 333-345.

Urzì-Brancati, C., A. Pesole \& E. Fernández-Macías (2019) Digital Labour Platforms in Europe: Numbers, Profiles, and Employment Status of Platform Workers, Report EUR 29810 EN, Brussels: Publications Office of the European Union, JRC117330.

Urzì-Brancati, C., A. Pesole \& E. Fernández-Macías (2020) New Evidence on Platform Workers in Europe: Results from the Second COLLEEM Survey, Report EUR 29958 EN, Brussels: Publications Office of the European Union, JRC 118570. 
Table 1: Column 1 (very light gray): Number of people signed-up to micro-working sites, worldwide. Source: websites of platforms included in analysis (accessed in August 2017 for Amazon Mechanical Turk; September 2018 for all other platforms). Columns 2-4 (light gray): Average monthly number of unique visitors on micro-work platforms (left), average duration of visits (centre) and average number of monthly unique visitors from France (right). Source: Authors' elaboration based on information from SimilarWeb.com, accessed in September 2018 and based on websites' audience tracking over JulySeptember 2018. Column 5 (gray): Estimated number of France-based registered users ${ }^{9}$.

$\begin{array}{llllll}\text { Platform } & \text { Registered users } & \begin{array}{l}\text { Average monthly } \\ \text { unique visitors }\end{array} & \begin{array}{l}\text { Average visit } \\ \text { duration (minutes) }\end{array} & \begin{array}{l}\text { Average monthly } \\ \text { unique French visitors }\end{array} & \begin{array}{l}\text { Registered } \\ \text { French users }\end{array} \\ \text { Amazon Mechanical Turk } & 500,000 & 588,976 & 34: 19 & \text { N/A } & 1,250 \\ \text { Microworkers } & 1,215,829 & 174,808 & 18: 22 & 1,835 & 12,766 \\ \text { Clickworker } & 1,200,000 & 242,579 & 07: 40 & 14,700 & 72,720 \\ \text { ClixSense } & 7,000,000 & 1,083,000 & 11: 05 & 20,250 & 130,900 \\ \text { Appen } & 1,000,000 & 260,699 & 05: 04 & 9,645 & 37,000 \\ \text { Foule Factory } & 50,000 & 7,647 & 26: 41 & 6,958 & 50,000 \\ \text { Ferpection } & 50,000 & 28,064 & 07: 10 & 8,116 & 14,460 \\ \text { Total } & \mathbf{1 1 , 0 1 5 , 8 2 9} & & & \mathbf{6 1 , 5 0 4} & \mathbf{3 1 9 , 0 9 6}\end{array}$

\footnotetext{
${ }^{9}$ Given the national scope of Foule Factory's activity, we consider all its registrations to be French. For Mechanical Turk we refer to the study of Difallah, Filatova \& Ipeirotis (2018) reported above. For all other platforms, we divide the number of visitors from France (column 4) by the total number of visitors (column 2), then multiply by the number of registrations (column 1). For example, Ferpection has 8,116 unique visitors from France, out of a total of 28,064 visitors, i.e. $28.92 \%$; multiplying by 50,000, its declared number of registered users, gives 14,460 .
} 